ECONOMIC GROWTH CENTER

YALE UNIVERSITY

P.O. Box 208629

New Haven, CT 06520-8269

http://www.econ.yale.edu/ egcenter/

CENTER DISCUSSION PAPER NO. 899

\title{
THE FOOD PROBLEM AND THE EVOLUTION OF INTERNATIONAL INCOME LEVELS
}

\author{
Douglas Gollin \\ Williams College and Yale University \\ Stephen L. Parente \\ University of Illinois \\ Richard Rogerson \\ Arizona State University
}

December 2004

Notes: Center Discussion Papers are preliminary materials circulated to stimulate discussions andcritical comments.

\begin{abstract}
We have benefited from the comments of Jeremy Atack, Robert Evenson, Tim Guinnane, B. Ravikumar, Diego Restuccia, and seminar participants at Brown University, Columbia University, Williams College, University of Delaware, CIRPEE-UQAM in Montreal, SUNY Albany, the NBER Summer Institute 2002, and annual meetings of the Allied Social Science Association, the Econometric Society, and the Society for Economic Dynamics. Part of this work was done while Gollin was visiting the Economic Growth Center at Yale. Rogerson acknowledges support from the NSF. Authors' addresses: Fernald House, Williams College, Williamstown, MA 01267; University of Illinois, 1206 S. Sixth St., Champaign, IL 61820; and Department of Economics, Arizona State University, Tempe AZ 85287. E-mail addresses: dgollin@williams.edu, parente@uiuc.edu, and richard.rogerson@asu.edu. We thank Stephanie Sewell for helpful research assistance. An earlier version of this paper circulated under the title, Structural Transformation and Economic Development.
\end{abstract}

This paper can be downloaded without charge from the Social Science Research Network electronic library at: http://ssrn.com/abstract=631205

An index to papers in the Economic Growth Center Discussion Paper Series is located at: http://www.econ.yale.edu/ egcenter/research.htm 


\title{
The Food Problem and the Evolution of International Income Levels \\ Douglas Gollin \\ Stephen L. Parente \\ Richard Rogerson
}

\begin{abstract}
This paper examines the effect of agricultural development on a country's overall development and growth experience. In most poor countries, large fractions of land, labor, and other productive resources are devoted to producing food for subsistence needs. This “food problem” can delay a country's industrial development for a long period of time, causing its per capita income to fall far behind the world leader. Once industrialization begins, this trend is reversed. The extent to which a country catches up to the leader depends primarily on factors that affect productivity in non-agricultural activities: agricultural productivity is thus largely irrelevant in the very long run. But in the short run, a country that experiences large improvements in agricultural productivity (due to, say, a Green Revolution) will experience a rapid increase in its income relative to the leaders.
\end{abstract}

Keywords: Agriculture, Economic Growth, Subsistence, Food Problem, Agricultural Technology, Long-run Growth

JEL Codes: E130, O400, O410, Q100 


\section{Introduction}

Many poor economies suffer from what T.W. Schultz (1953) characterized as the “food problem.” Simply put, Schultz argued that many poor countries are in a situation of "high food drain," in which they have "a level of income so low that a critically large proportion of the income is required for food." Schultz took it as given that countries in this situation must produce the bulk of their own food to satisfy subsistence needs, presumably because imports are prohibitively costly and because these countries have few goods or resources to exchange for food. Until they can meet their subsistence needs, Schultz said, they are unable to begin the process of modern economic growth.

Schultz’s view was later echoed in a large literature on development, which held that an agricultural surplus is a necessary condition for a country to begin the development process. The hypothesis was a central argument of Johnston and Mellor (1961), Johnston and Kilby (1975) and Timmer (1988), among others. More recently, it has figured prominently in the writing of non-economists such as Diamond (1997).

This paper explores the quantitative plausibility of Schultz's hypothesis. In particular, it puts forth a model of economic development and growth that implements Schultz's idea, and then uses the model to organize and interpret the evolution of international incomes over the last three centuries. We show that the model offers useful insights into the evolution of international income levels. In particular, we show that the 
model offers a plausible explanation for why some countries started to realize increases in per capita output much later in history than others; why once under way, structural transformation and the process of economic development proceed at different rates in different countries, the consequences of which are that some countries have continued to lose ground relative to the leader in terms of per capita output, some have gained ground, while others have neither gained or lost ground; and why some countries underwent growth miracles in the second half of the twentieth century.

The model we put forth is an extension of the neoclassical growth model that includes an agricultural sector. In both sectors, technology grows exogenously. We implement Schultz’s idea by imposing a subsistence food requirement for consumers in the model economy. The subsistence constraint implies that resources cannot move out of agriculture if productivity there is too low to meet the food requirements of the population.

The model allows for a potentially long period of constant living standards in which subsistence agriculture is the sole economic activity. As time passes and the levels of the two technologies grow, the economy experiences a prolonged period in which it undergoes a structural transformation from a subsistence economy to a modern industrialized economy. The structural transformation begins in an economy once productivity in the agricultural sector reaches the level needed to meet the food requirements of the population. At this date the economy begins to realize increases in per capita output.

Once the structural transformation begins, the economy steadily shifts labor from agriculture into industry. The rate at which this sectoral transformation takes place - and 
at which per capita income grows - depends importantly on the exogenous rate of technological change in the agricultural sector as well as on productivity in the nonagricultural sector. Productivity in the non-agricultural sector matters because the nonagricultural good can be used as an input into agricultural production (e.g., mechanization). Asymptotically, agriculture’s share of economic activity declines to zero and the model behaves like the standard one-sector neoclassical growth model.

The model predicts that all countries eventually make the transformation to a modern industrialized economy. Countries differ in the starting date of this transformation because of differences in climate, land quality, population density, policy, and institutions - all of which affect productivity in the agricultural sector. Countries differ in the speed at which the transformation proceeds because of differences in policies and institutions that affect productivity in the non-agriculture sector. Differences in nonagricultural productivity also determine long-run (asymptotic) differences in per capita incomes.

According to the model, the gap in per capita income between a late starter and an early starter may either increase or decrease while the late starter undergoes its structural transformation. This depends on the level of non-agricultural productivity in the late starter relative to the early starter. A late-starting country with a sufficiently high level of non-agricultural productivity (relative to an early starter) can experience a growth miracle and eliminate much of the income gap with the early starter.

A late starter can also realize a growth miracle by increasing its level of agricultural productivity, whether by improving policies or gaining an unexpected increase in its level of agricultural technology. (For example, a technology-driven Green 
Revolution can lead to a growth miracle.) However, a growth miracle induced by an increase in agricultural productivity differs in important ways from a growth miracle induced by an increase in industrial productivity. In particular, productivity improvements in agriculture can deliver a rapid "growth miracle" that shifts many workers out of agriculture, but these benefits do not translate into long-run increases in income. By contrast, high productivity in the non-agricultural sector will have small immediate effects in economies that are largely agricultural, but this will have large longrun consequences for a country's income level.

Our paper clearly owes a major intellectual debt to the early (but often less formalized) literature on agricultural development. ${ }^{1}$ It is also related to a set of recent papers that seek to account for the process of economic development and growth in the very long run. Most of these papers seek to encompass, in a single model, the fact that living standards in most economies were low and relatively constant for long periods of time, followed by a transition period with modest and irregular growth, followed in turn by a period of modern economic growth. This set of papers includes: Galor and Weil (2000), Goodfriend and McDermott (1995), Hansen and Prescott (2002), King and Rebelo (1993), Laitner (2000), and Lucas (2001). These papers differ fundamentally from our paper in that they do not formally model an agriculture sector that coexists with the industrial sector. Our paper also relates to a set of recent papers that incorporate agriculture into growth models. This set of papers include: Caselli and Coleman (2001), Echevarria (1995, 1997), Kongsamut, Rebelo and Xie (2001), Irz and Roe (2001), Glomm (1992), King and Rebelo (1993), and Matsuyama (1992). With the exception of 
Caselli and Coleman, none of these papers offer insight into the role of agriculture in the evolution of international income differences. ${ }^{2}$ Caselli and Coleman (2001) do this to some extent, although they examine the evolution of relative incomes across regions in the United States. They do not focus on the food problem, but instead focus on skills acquisition as a necessary condition for industrialization.

Our paper is most closely related to Gollin, Parente, and Rogerson (2002), and Kogel and Prskawetz (2001). These papers similarly impose a subsistence constraint within a modern growth model and allow for exogenous technological change in the agricultural sector. Gollin et al. (2002) also use the model to interpret the evolution of international income differences. The main difference between our paper and these is that the earlier papers do not allow a feedback from industry to agriculture corresponding to the mechanization of farming.

Finally, this paper takes note of recent observations that economic growth does not come entirely from the manufacturing sector. Martin and Mitra (1999) find that TFP growth in agriculture exceeds that in manufacturing, in a cross-section of countries at varying levels of income. Similarly, Bernard and Jones (1996) find that agricultural TFP growth is higher than non-agricultural TFP growth in a sample of 14 OECD countries for a period from 1970-87. Our model differs from most recent growth papers in that it allows for this channel of economic growth.

\footnotetext{
${ }^{1}$ In addition to Schultz (1953) and Schultz (1968), important contributions include Johnston and Mellor (1961), Fei and Ranis (1964), Schultz (1964), Lewis (1965), Kuznets (1966), Chenery and Syrquin (1975), Johnston and Kilby (1975), Hayami and Ruttan (1985), Mellor (1986), Timmer (1988), and Syrquin (1988).

${ }^{2}$ We note with irony that Schultz, in 1964, could write: "Growth economists have been producing an abundant crop of macro-models that are, with few exceptions, neither relevant in theorizing about the growth potential of agriculture nor useful in examining the empirical behavior of agriculture as a source of growth.” A similar comment could easily have been made 30 or 40 years later.
} 
The paper is organized as follows. Section 5 provides some empirical support for the food problem hypothesis. Section 3 describes the model economy and characterizes the equilibrium properties. Section 4 calibrates the model to the structural transformation of the United Kingdom over the period from 1750 to 2000. Section 5 then uses the calibrated model of economic development and growth to organize and interpret the evolution of international incomes levels over the last 250 years. Finally, Section 6 concludes the paper.

\section{Empirical Support}

The central tenet of our theory is that improvements in agricultural productivity allow resources to be released to other activities. Before proceeding, it is instructive to ask what the empirical support is for this proposition. In this section we document two facts about the agricultural transformation. First, in most poor countries, large amounts of labor and land are devoted to the production of basic foods for domestic consumption - in other words, to meeting subsistence needs. Second, increases in the productivity of the agricultural sector are associated with a structural transformation: the shifting of resources away from agriculture and into non-agriculture. We consider these two facts in turn.

Subsistence needs

In most poor countries, agriculture accounts for very large fractions of employment and value added. For all developing countries in 2000, the United Nations Food and Agriculture Organization (FAO) estimates that agriculture accounted for 55 percent of employment, and for 65 countries designated as "low-income,” agriculture employed 58 percent of the total workforce (FAOSTAT data, 2004). For a number of countries 
(including Rwanda, Burundi, Burkina Faso, and Nepal), over 90 percent of workers are employed in agriculture. Agriculture's share of value added is also high - reaching 40-50 percent in some poor countries.

Some agriculture is devoted to producing non-food crops and export crops, which might challenge our underlying assumption that the agriculture sector essentially produces food for domestic consumption. But it turns out that in most poor countries, agricultural land and labor are overwhelmingly devoted to food production - and specifically, to meeting the subsistence needs of the population. For example, FAO reports that in 2000, 68.6 percent of arable land in 159 developing countries was devoted to staple food crops: grains, pulses (beans, peas, lentils, etc.), roots and tubers (FAOSTAT data, 2004). ${ }^{3}$ Of the resulting production, almost all was devoted to domestic consumption: only a handful of developing countries were net exporters of grain (Argentina, Guyana, India, Paraguay, Thailand, Uruguay, and Vietnam). ${ }^{4}$ Of these, only Argentina exported more than a quarter of its grain production (FAOSTAT 2001). A similarly small set of countries were significant net exporters of roots and tubers, with only eight countries having net exports equal to more than 5 percent of production (Costa Rica, Dominican Republic, Guatemala, Lebanon, St. Vincent, Swaziland, Thailand, and Vietnam).

Other statistics support the same basic point: in today's poor countries, an overwhelmingly large fraction of the resources in agriculture are used for meeting

\footnotetext{
${ }^{3}$ The United Nations Food and Agriculture Organization (FAO) includes data for 159 developing countries. The major countries missing from the data are the countries of the former Soviet Union. ${ }^{4}$ A number of countries from the former Soviet Union, not included in the land use data above, are modest exporters of grain, including Ukraine and Kazakhstan.
} 
domestic food needs. Moreover, the resources required are large, relative to the aggregate economy.

Agricultural productivity growth and the structural transformation

On average, countries that have succeeded in increasing productivity in agriculture have experienced relatively sharp declines in agriculture’s share of GDP. In other words, growth in agricultural productivity has been associated with a diminishing role for agriculture. This result is fairly robust to the ways in which we measure agricultural productivity, and it mirrors results reported by Timmer (1988), among others.

Our analysis is based on data on a set of 62 countries defined as developing by the Food and Agriculture Organization (FAO) of the United Nations and for which all relevant data were available. Table 1 reports the results of an OLS regression on the data, for the 1960-90 period. The results show a negative and significant relationship between the change in agriculture's share of employment and the change in agricultural output per person. ${ }^{5}$ A similar (stronger) result obtains if we use agricultural output per worker on the right-hand side, although this variable by construction is linked with agriculture's share of employment. ${ }^{6}$

The implication is that countries experiencing increases in agricultural productivity are able to release labor and other resources from agriculture into other sectors of the economy. This finding is particularly important because the data suggest that in most poor countries, output per worker in non-agriculture is far higher than in agriculture. This

\footnotetext{
${ }^{5}$ Agriculture's share of employment is a useful measure of agriculture's importance in economic activity. The other commonly reported measure - agriculture's share of GDP - is directly related to increases in productivity and thus is a less attractive measure of agriculture's importance in the economy.
} 
means that a shift of workers from agriculture to non-agriculture increases average productivity in the economy. For example, shifting a worker from agriculture to nonagriculture in 1960 would have tripled his or her output in Korea or Malaysia; it would have increased it by a factor of nine in Thailand.

\section{A Model of Structural Transformation}

\subsection{The Economy}

Our model is an adaptation of those of Laitner (2000) and Hansen and Prescott (2002). The basic structure of our model is that of the one-sector neoclassical growth model, extended to allow for an explicit agricultural sector in addition to the usual nonagricultural sector. The extension is done in such a way that the process of development is associated with a structural transformation of economic activity, characterized by a declining share of economic activity accounted for by the agriculture. Asymptotically, agriculture's share of the labor force shrinks to zero, and the model becomes identical to the standard one-sector neoclassical growth model. ${ }^{7}$

Economies are treated as being closed. Hence, each economy is required to produce its own food. This assumption precludes a poor country that is relatively unproductive at producing food from simply importing it, a restriction that can be significant for some specifications of our model. However, this assumption is consistent with the data: the evidence is that imports of basic foodstuffs tend to be quite small in developing countries. For example, FAO data show that, taking all low-income countries together, net imports

\footnotetext{
${ }^{6}$ This also supports the notion that the increase in agricultural productivity is not occurring simply because unproductive labor is being removed from the sector.
} 
of food supplied around 5 percent of total calorie consumption in 2000 (FAOSTAT data, 2004). Using another measure of import dependence, in 2000, there were exactly 100 with populations over 5 million and available FAO data on food consumption. Of these, only 14 imported more than 15 percent of their total food grain, and only 7 of these were developing countries (Angola, Belarus, Cuba, Dominican Republic, Libya, Malaysia, and Saudi Arabia). Including small countries as well as large, approximately 375 million of the world's 6 billion people live in countries that depend on imports for more than 15 percent of food grain consumption. Thus, we believe it is empirically reasonable to treat our model economy as closed to trade in food. ${ }^{8}$

\section{Preferences}

The model economy is populated by an infinitely-lived representative family. Instantaneous utility is defined over two consumption goods: a non-agricultural good denoted by $c_{t}$, and an agricultural good denoted by $a_{t}$. To account for the secular decline in agriculture's share of economic activity we follow the convention of assuming a utility function with non-homothetic preferences, similar to the familiar Stone-Geary specification. To keep the analysis simple, we adopt a rather extreme functional form, namely ${ }^{9}$,

\footnotetext{
${ }^{7}$ In reality it may be that although agriculture's share of economic activity becomes small, it remains bounded away from zero. This would not matter at all for our analysis.

${ }^{8}$ We do not attempt to model why a country that might benefit from food imports chooses not to do so. One set of explanations might involve trade barriers or policy distortions. An alternative and compelling story is simply that transport costs and infrastructure stocks make it infeasible to deliver imported food to population centers at prices that compete with domestic production - at least for countries with sizable populations living in interior regions. Countries with large fractions of their population inhabiting coasts with good ocean access (e.g., Hong Kong, Singapore) may not face the "food problem."

${ }^{9}$ Technically we should assume that a family has a very small endowment of the nonagricultural good that is always consumed to avoid the issue that instantaneous utility is lowered when c increases from zero to a small positive amount. We ignore this for simplicity.
} 


$$
U\left(c_{t}, a_{t}\right)=\left\{\begin{array}{lll}
\log \left(c_{t}\right)+\bar{a} & \text { if } a_{t}>\bar{a} \\
a_{t} & \text { if } & a_{t} \leq \bar{a}
\end{array} .\right.
$$

Lifetime utility is given by:

$$
\sum_{t=0}^{\infty} \beta^{t} U\left(c_{t}, a_{t}\right)
$$

where $\beta$ is the subjective time discount factor.

These preferences imply that a family will never consume the agricultural good beyond $\bar{a}$ no matter how cheap agricultural goods may be relative to nonagricultural

goods. In equilibrium this will imply that once output in the agricultural sector reaches $\bar{a}$, all remaining labor will flow out of agriculture regardless of the state of the nonagricultural sector. More generally, one might expect that a very low level of relative productivity in the non-agriculture sector might cause more labor to be allocated to agricultural production as consumers shift their consumption bundles toward agricultural goods. This is potentially an important effect and one that we focused on in Gollin, Parente and Rogerson (2004). We abstract from it here, not because we believe it is insignificant, but rather because we want to focus attention on the reallocation of labor and capital, rather than consumption.

\section{Endowments}

The representative family is endowed with one unit of time each period. Additionally, the family is endowed with the economy's stock of land, denoted by $L$, which is normalized to 1. Land does not depreciate in the model. The family is not endowed with any initial holdings of capital. It will, however, come to own capital at some date. 


\section{Technologies}

\section{Non-Agriculture}

Following the tradition in the literature, we associate o the nonagricultural sector with the "manufacturing" or "industrial" sector, though in fact it is meant to capture the full range of activities in manufacturing, mining, services, and other nonagricultural sectors. We use the subscript $m$ to refer to non-agricultural variables. The nonagricultural sector produces output $\left(Y_{t}\right)$ using capital $\left(K_{m t}\right)$ and labor $\left(N_{m t}\right)$ as inputs according to the following constant returns to scale technology:

$Y_{t}=E_{m}\left[\left(1+\gamma_{m}\right)^{t} K_{m t}^{\theta} N_{m t}{ }^{1-\theta}+\varepsilon N_{m t}\right]$

In equation (3), $E_{m}$ is an efficiency parameter that determines total factor productivity in the non-agriculture technology, and $\gamma_{m}$ is the constant exogenous rate of technological change. ${ }^{10}$ This technology is standard except for the term $\varepsilon N_{m t}$. This term is added to the production function so that an economy with no physical capital can start manufacturing and accumulate capital. In the numerical work that follows we will pick $\varepsilon$ to be a small number. $^{11}$

The efficiency parameter, $E_{m}$, is assumed to be country-specific, being determined by policies and institutions that impact on activity in the non-agriculture sector. ${ }^{12}$ It can be

\footnotetext{
${ }^{10}$ We abstract from issues such as embodiment of technology and appropriate technology.

${ }^{11}$ Alternatively, we could have assumed that all countries are naturally endowed with a very small amount of capital that is always available. This would not affect our results at all.

${ }^{12}$ See Parente and Prescott (2000) for an explicit discussion of a mapping from policies into the level of efficiency at the aggregate level. Certainly, an important issue in this literature is to identify those policies and institutions that are most responsible for generating cross-country differences in efficiency. While we believe this remains an important issue in this literature, it is not central to our purpose, and hence we feel the reduced form approach makes our analysis more transparent.
} 
interpreted as the fraction of the exogenous stock of knowledge in the world that a country would use, given its institutions, were it to produce the non-agricultural good. In contrast, the parameters $\gamma_{m}$ and $\varepsilon$ are identical across countries. To be sure, the growth rate of productive knowledge has not been constant through history. The assumption of a constant rate of technological change, however, is not critical to the results we establish in this paper. Additionally, much of the stock of useful knowledge owes its creation to research and development in the rich countries. Poor countries are generally not in the business of creating ideas, and so from their perspective, the assumption of exogenous technological change is reasonable.

Output from the manufacturing sector can be used for consumption or to augment the capital stock. The non-agriculture resource constraint is thus,

$$
c_{t}+x_{t} \leq Y_{t,},
$$

and the law of motion for the stock of capital in the economy is

$$
k_{t+1}=(1-\delta) k_{t}+k_{t} .
$$

\section{Agriculture}

We distinguish between three technologies to produce the agricultural good. The first of these, which is indexed by 0 , corresponds to a traditional, or Malthusian, technology. For this technology, we think of the household itself as the production unit, consuming all that it produces. The key features of this technology are that it is not subject to exogenous technological change and it is not affected by policy. The inputs to the traditional technology are labor services $\left(N_{0 t}\right)$ and land services $\left(L_{0 t}\right)$. The amount of output produced from the traditional technology $\left(A_{0 t}\right)$ is given by

$$
A_{0 t}=N_{0 t}^{\alpha} L_{0 t}^{1-\alpha}
$$


We assume that when all of the economy's labor and land are employed in the traditional technology the economy produces $\bar{a}$ units of the agricultural good. Given our normalization of the family's endowments of time and land, this assumption implies $\bar{a}=1$. There is nothing particularly special about this normalization. Our results would not be much affected by alternatively introducing a TFP parameter to the traditional technology and using a different value for $\bar{a} \cdot{ }^{13}$

The other two agricultural technologies, indexed by the numbers 1 and 2, are both subject to exogenous technological change and are affected by policy. The key difference between them is that Technology 2 uses land, labor, and capital produced in the manufacturing sector whereas Technology 1 uses only land and labor.

We think of Technology 1 as essentially an intensification of traditional agriculture, in the sense described in the early development literature by Ester Boserup (1965) and Clifford Geertz (1966). We associate Technology 1 with the family farm that produces more than its members working on the farm consume. Intensification occurs in this stage through shortening of fallows, improved manipulation of crop rotations, manures and organic fertilizers, and construction of terraces, bunds, drains, and other land modifications. Hayami and Ruttan (1985) note that this stage of technological advance was critical in the English agricultural revolution. They further note that "[t]he net effect was a substantial growth in both total agricultural output and output per acre.” They further note that "[t]he inputs used in this conservation system of farming were largely supplied by the agricultural sector itself."

\footnotetext{
${ }^{13}$ We note that there are reasons to believe that a value close to $\bar{a}$ is appropriate. Models in which fertility is endogenous suggest that output per capita will be close to subsistence levels for economies that have not begun the process of industrialization.
} 
By contrast, Technology 2 involves the use in agriculture of manufactured capital goods. We think of this technology as reflecting the introduction of manufactured farm implements, transport equipment, processing machinery, etc. To some degree, we also think of the introduction of chemical fertilizers as a kind of capital, in the sense that they allowed farmers to build up soil fertility (or to reduce nutrient loss) on continuously farmed land.

Agricultural output from Technology $1\left(A_{1 t}\right)$ is given by

$$
A_{1 t}=E_{a}\left(1+\gamma_{a}\right)^{t} N_{1 t}^{\alpha} L_{1 t}^{1-\alpha},
$$

whereas agricultural output produced using Technology $2\left(A_{2 t}\right)$ is given by

$$
A_{2 t}=E_{a}\left(1+\gamma_{a}\right)^{t} K_{2 t}^{\phi} N_{2 t}^{\varphi} L_{2 t}^{1-\phi-\mu} .
$$

In equations (7) and (8), $E_{a}$ is an efficiency parameter, which is country-specific. As was the case with the manufacturing technology, one source of cross-country differences in this parameter is policies and or institutional features that impact on agricultural activity. However, another very important source of variation is differences in the amount or quality of land per person, and climate. In particular, technological innovations that are useful for a specific crop in a given climate may not be particularly relevant for other crops in other parts of the world, thus generating large differences in cross-country productivity levels that are independent of policy.

The parameter $\gamma_{a}$ denotes the rate of exogenous technological change in the modern agricultural technologies. Though it is easy to imagine circumstances in which (because technological innovations are not applicable in all countries) growth rates of technology may differ across countries, for the purposes of our analysis here, we assume that this value is common to all countries. 
There are several reasons why we use two "modern" agricultural technologies rather than one. The first reason is purely technical. We need to allow for some mechanism by which the structural transformation can begin. If the agricultural technology given by equation (7) did not exist, no economy would ever be able to move resources out of agriculture and grow. ${ }^{14}$ Second, as evidenced both by England's historical experience and by the more recent experience of the Green Revolution in developing countries, major increases in output can be realized without significant manufactured inputs. For example, in the Green Revolution, large increases in rice harvests followed the introduction of new seed varieties - even in places where farmers continued to use animal power and hand tools.

In the model economy, output from the agriculture sector can only be used for consumption purposes. The agriculture resource constraint for the economy is simply $a_{t} \leq \sum_{i=0}^{2} A_{i t}$. The assumptions we make on the economy imply that the traditional technology will not be used in equilibrium if either of the modern technologies is used.

\subsection{Solving for Equilibrium}

We focus on the competitive equilibrium for this economy. Solving the competitive equilibrium is fairly straightforward. As long as $E_{a}\left(1+\gamma_{a}\right)^{t}<1$, an economy will specialize in agriculture using the traditional technology in order to meet its subsistence needs. The economy will switch into agricultural Technology 1 in the first period for

\footnotetext{
${ }^{14}$ Alternatively, Technology 1 could be dropped from the model economy by assuming the traditional technology is subject to technological change after some date
} 
which $E_{a}\left(1+\gamma_{a}\right)^{t} \geq 1$, and will begin manufacturing in the first period in which $E_{a}\left(1+\gamma_{a}\right)^{t}>1$

Denote the first period in which the economy can move resources into manufacturing by $T$. The competitive equilibrium allocations solve the following planner's problem starting with $T$ :

$$
\max \sum_{t=T}^{\infty} \beta^{t-T}\left[\log \left(c_{t}\right)+\bar{a}\right]
$$

subject to

i. $c_{t}+k_{t+1} \leq E_{m}\left(1+\gamma_{m}\right)^{t} K_{m t}^{\theta} N_{m t}^{1-\theta}+\varepsilon E_{m} N_{m t}+(1-\delta) k_{t}$

ii. $E_{a}\left(1+\gamma_{a}\right)^{t} N_{1 t}^{\alpha} L_{1 t}^{1-\alpha}+E_{a}\left(1+\gamma_{a}\right)^{t} K_{2 t}^{\phi} N_{2 t}^{\mu} L_{2 t}^{1-\phi-\mu} \geq \bar{a}$

iii. $K_{m t}+K_{2 t} \leq k_{t}$

iv. $N_{m t}+N_{1 t}+N_{2 t} \leq 1$

V. $L_{1 t}+L_{2 t} \leq 1$

vi. $\mathrm{k}_{T}=0$.

The maximization is over the sequence of choices $\left\{c_{t}, K_{m t}, K_{2 t}, N_{m t}, N_{1 t}, N_{2 t}, k_{t+1}\right\}_{t=T}^{\infty}$.

Let the numeraire for the economy be the agricultural good. Prices can be determined as follows. First, the rental prices of land and labor are just the marginal physical products from the agricultural technology that is used. Second, the price of the manufactured good can be determined by using the marginal physical product of labor from agriculture with the marginal physical product of labor from manufacturing. The rental price of capital is just the marginal product of capital in agricultural Technology 2 as long as that technology is used. Otherwise, it is the price of the manufactured good times the marginal physical product of capital in manufacturing. 
Computationally, we exploit the fact that in the limit the economy converges to the one-sector neoclassical growth model. We employ a shooting algorithm in which only a guess for the value for $k_{T+1}$ is needed to compute the entire path of allocations for the economy from $t=T$ to $t=T+350$. As part of this algorithm, we determine for any $k_{t}$ the optimal allocations of capital, labor and land service inputs for all technologies

\section{Model Calibration}

In this section we calibrate the model to the experience of the United Kingdom over the last 200 years and show that the model replicates the long run pattern of economic development and growth. Namely, we show that the model can account for the long initial period of constant living standards, followed by a transition period with small and irregular increases in per capita income, followed by period of modern economic growth with constant and large increases in per capita income.

\subsection{Parameter Values}

The empirical counterpart of the model period is a year. The strategy of the calibration exercise is to restrict the values of the preference parameters and the parameters associated with the manufacturing side of the economy to match twentieth century observations of the United Kingdom and other currently rich industrialized nations. The values of the parameters associated with the agricultural side of the economy are restricted so that the model matches the structural transformation of the United Kingdom, and estimates of agricultural production functions by Hayami and Ruttan (1985). Table 2 reports the values of the parameters. A detailed explanation of how the value of each parameter was selected is as follows. 


\section{Preference Parameters}

There are two preference parameters: the subjective time discount factor, $\beta$ and the

subsistence agriculture parameter, $\bar{a}$. The subsistence agriculture parameter is normalized to 1 , because its value determines the units in which the agricultural good is measured. The value of the subjective discount factor, $\beta$, is set so that the real interest rate (measured in the non-agricultural good) implied by the model asymptotically equals the real interest rate in the rich industrialized countries over the twentieth century of 5 percent.

Agricultural Sector Parameters

There are five parameters associated with the agricultural sector: the labor share parameter associated with both the traditional agricultural technology, and modern Technology $1, \alpha$; the exogenous rate of technological change, $\gamma_{a}$; the efficiency parameter associated with the modern agricultural technologies, $E_{a}$; and the capital share and labor share parameters associated with the modern agricultural Technology 2, $\phi$ and $\mu$. We take the value of the labor share parameter, $\alpha$, from historical estimates of labor and land shares by Clark (1998). The share parameters, $\phi$ and $\mu$, associated with modern Technology 2 are based on estimates of aggregate agricultural production functions by Hayami and Ruttan (1985). The parameters $E_{a}$ and $\gamma_{a}$ are set so that the model matches UK agriculture employment shares in 1800 and 1950, which are reported by Kuznets (1966) to be 35 percent and 5 percent respectively.

Non-Agricultural Parameters 
There are five parameters associated with the non-agricultural production: the exogenous rate of technological change, $\gamma_{m}$; the depreciation rate, $\delta$; efficiency, $E_{m}$; the labor productivity parameter, $\varepsilon$; and the capital share parameter, $\theta$. The value for $\gamma_{m}$ is set so that asymptotically the growth rate of per capita output implied by the model matches the growth rate of per capita output in the United Kingdom over the latter part of the twentieth century reported by Maddison (1995). The depreciation rate is set to the standard value of 0.065 . The labor productivity parameter, $\varepsilon$, is set to 0.0001 . The motivation for this choice is that the parameter must be non-zero so that the economy can accumulate capital starting with no capital, but it should be close to zero so that it does not affect the model's predictions once the economy has a positive capital stock.

The value of $E_{m}$ affects the rate at which the structural transformation occurs, and the date at which the economy first begins using the mechanized agricultural production technology. Consequently, the value of the efficiency parameter can be restricted by requiring the date at which the switch to Technology 2 is made in the model matches the date at which farming was mechanized in the United Kingdom. The economic history literature offers conflicting views on when this switch actually occurred. It is clear that some manufactured capital goods have been used in agriculture for a very long time, but the major transformation of the technology - to one making routine and extensive use of manufactured capital goods - appears to have happened after the late 1700s and to have been complete by the middle of the $19^{\text {th }}$ century. Robert C. Allen (1999) has argued convincingly that 1800 marks an important break-point in the English historical data, with a "post-1800 surge in productivity" in agriculture contributing significantly to overall economic growth after 1815. A key part of this productivity surge appears to be 
the contribution of early mechanization, such as the rapid improvement in plough designs documented by Brunt (2003), who notes that by 1850, “agricultural implements were an important part of England's inventory of advanced machinery, which was the envy of the world.” In our calibration exercise, then, we take 1800 as the date of England's transition to Technology 2.

The value of the capital share is not well restricted by the national income and product accounts (NIPA). The main reason for this is that the NIPA measure investment in only one form of capital, namely physical capital. Intangible capital investments, for example, worker training, R\&D expenditures, and software purchases are treated as ordinary business expenses, and thus go unmeasured in the NIPA. Our strategy in the calibration is to set $\theta=.50$ for the benchmark case and then examine the sensitivity of the model to alternative values of the capital share parameter where ever appropriate.

The reason we use $\theta=.50$ for the benchmark is that this value implies that asymptotically investment in intangible capital is the same size as investment in physical capital, and that the ratio of investment in physical capital to GDP implied by the model matches the ratio of 20 percent observed in the data. ${ }^{15}$ By restricting the value of the total capital share in this way, it is possible to decompose $\theta$ into its intangible capital and tangible capital components, $\theta_{\mathrm{z}}$ and $\theta_{k}$, where $\theta_{k}+\theta_{\mathrm{z}}=\theta$. For the benchmark, the implied value of $\theta_{k}$ is 0.24 . Given this decomposition, it is possible to decompose total investment into its intangible and tangible capital components at any date along the equilibrium path. This is important because intangible capital investment must be

\footnotetext{
${ }^{15}$ See Parente and Prescott $(1994,2000)$ for a formal discussion of the size of the intangible capital stock and its implications for total capital's share.
} 
subtracted from output in the model when comparisons between the model and the actual data are made.

\subsection{Economic Development and Growth}

In our calibration, the first year in which resources are moved out of agriculture in the United Kingdom is 1708 . Prior to 1708 , the model predicts a constant living standard at a subsistence level, which (like many other points) is a subject of some debate in the literature on English economic history, but which seems a reasonable abstraction. ${ }^{16}$ After 1708, the model economy shows a steady but modest intensification of agriculture, with rising output per worker, and the beginning of non-agricultural production. By the process of the calibration, the first year in which agriculture starts using physical capital is 1800 . Technology 1 continues to be operated for the next 5 years. Thereafter, all the economy’s agricultural output is produced using Technology 2.

Figures 1-3 compare the time series generated by the model to UK data taken from Kuznets (1966) going back to 1800. Despite the model's simplicity, it matches the UK development and growth experience closely over the last 200 years. Figure 1 displays agriculture's employment share. By the process of the calibration, the model trivially matches agriculture's share of employment in 1800 and 1950. As can be seen, the model's predictions for the period between 1820 and 1950, and the period after 1950 are also very close to the actual data. Figure 2 displays the path of per capita output over the 1820-1990 relative to the 1820 value. As can be seen, the model matches the path of UK

\footnotetext{
${ }^{16}$ For example, Allen (1999) writes that “[c]onsumption of agricultural goods per head fell in the sixteenth and seventeenth centuries and then rebounded, but the level reached in the early eighteenth century was no higher than that of the sixteenth.”
} 
output fairly closely except for the period comprising the two World Wars. ${ }^{17}$ The growth rate of per capita output during the nineteenth century predicted by the model is lower compared to the growth rate in the twentieth century, just as it is in the data. Finally, Figure 3 displays agriculture's share of output at each date, measured in date $t$ prices. Here, too, the model, despite its rather simple structure, does a fairly good job at matching the decline in agriculture's share of output. These findings are robust to alternative values for the non-agriculture capital share parameter, $\theta$.

The equilibrium paths of prices for the model economy are consistent with the growth experiences of the currently rich industrialized countries. The real wage increases continuously once the structural transformation begins, increasing by a factor 30 between 1708 and 2000. Neither the rental price of land, nor the relative price of the nonagricultural good, nor the real interest rate display much change once the economy starts using agricultural Technology 2. The relative price of the non-agricultural good decreases monotonically at an average annual rate of .07 percent, whereas the real interest rate declines from 5.6 to 5.0 percent.

\section{The Evolution of International Income Levels}

In this section we use the model to organize and interpret the evolution of international income levels over the last three centuries. In particular, we use the model to account for the following aspects of the evolution of international income levels:

\footnotetext{
${ }^{17}$ It is well known that the British economy grew well below trend values during the interwar period, a phenomenon that is still subject to some debate and one that our calibration does not attempt to capture.
} 
- Economic growth started in different countries at different times with some countries starting to grow approximately 250 years after the United Kingdom started.

- Late starters' experiences have differed dramatically once economic growth began. Some countries - particularly those in Latin America started economic growth around 1900, and subsequently maintained the same level of income relative to the leader. Other countries - particularly those in South East Asia - started to grow in the first half of the twentieth century and subsequently eliminated much of the gap with the leader. A third set of countries, particularly sub-Saharan countries, started growth only after 1950, and subsequently lost ground relative to the leader.

- Some of the late starters that eliminated much of their income gap with the leader have done so in an incredibly short time, doubling their per capita income in a decade. These growth miracle experiences are a very recent phenomenon and are limited to countries that were poor at the time their miracle started.

We now interpret each of these facts in turn.

\subsection{Late Starts to Development}

According to the model the date at which an economy begins to industrialize is determined solely by the agriculture efficiency parameter. None of the parameter values associated with the non-agriculture technology affects this date. Consequently, we 
interpret delays in the starting date of economic growth as the outcomes of low efficiency in the agricultural sector.

We now explore the relative disparities in agricultural productivity needed to account for given delays in the start of economic development. Table 3 reports the implied value of agricultural productivity needed to make a country begin its structural transformation in 1800, 1850, 1900, 1950 and 2000. Recall that the calibration implies a 1708 starting date for the leader. The only parameter that differs between these economies is the agricultural productivity level, given by $E_{a}$. The non-efficiency component of agricultural TFP, namely, $\left(1+\gamma_{a}\right)^{t}$ is the same across countries at all dates. Table 3 also reports the late starter's relative income at the starting date. Relative income for each distorted economy is computed using year 2000 prices from the benchmark economy.

Are these factor differences in relative agricultural efficiency plausible? We are unaware of any study that computes Solow residuals associated with agricultural production in a cross section of countries. ${ }^{18}$ Those studies that compute Solow residuals associated with an aggregate production function for a cross section of countries (see for example, Hall and Jones 2000), find that factor difference in relative efficiencies between rich and poor countries to be as much as five. In light of this finding, the factor differences in agricultural efficiency implied by the model to account for the extremely late starts some countries have had seem plausible. From a quantitative perspective, this seems to support the longstanding idea in the development literature that agricultural

\footnotetext{
${ }^{18}$ Some crude comparisons, however, suggest that these numbers are not out of line with reality. Prasada Rao (1993) found that agricultural output per worker, measured in PPP terms, was more than 100 times higher in leading countries than in the poorest. Similarly, FAO data (FAOSTAT data, 2004) show that cereal yields in the highest-productivity countries were 20 times higher than in the lowest-productivity countries, for 2000.
} 
productivity differences - whether induced by nature or by policy - are a major reason that some countries are so poor.

Note that the subsistence constraint is important for this result. In general, if one economic activity is hindered by low productivity or policy distortions, economic agents will devote fewer resources to that activity and more to alternative activities, thereby lessening the impact of the "problem." However, in our model, output from agriculture is necessary and hence the economy cannot substitute away from it. Moreover, if productivity in agriculture goes down, then there will actually be an increase in the number of resources devoted to that activity.

\subsection{Development Subsequent to Late Start}

Although a country's efficiency in non-agriculture is unimportant for determining the date at which its begins its structural transformation and starts to grow, it is critical for determining its subsequent path of development - and in particular for whether it continues to lose ground or gain ground relative to the leader. Accordingly, we interpret the very different development experiences of late starters (subsequent to starting the process of economic development) as resulting from different non-agricultural efficiencies.

We now consider the impact of non-agricultural efficiency on a country's subsequent development and structural transformation. Towards this end, we compute the equilibrium for a number of economies all of which begin the process of industrialization in 1950 but which differ in non-agricultural efficiency. The values of $E_{m}$ we consider are $1 / 8,1 / 4$ and $1 / 2$ the level of the benchmark economy. Figure 4 shows relative per capita 
GDP and Figure 5 shows agriculture's share of employment for these economies over the 1950-2050 period. For each economy, per capita GDP in date $t$ is expressed relative to date $t$ per capita GDP for the benchmark economy, using year 2000 prices in the benchmark economy.

A country's relative efficiency in non-agricultural efficiency has important implications for its development path once its structural transformation has begun. For the economy with $E_{m}=1 / 8$ the leader's level, relative per capita GDP continues to fall over the industrialization process. For the economy with $E_{m}=1 / 4$ the leader's level, relative per capita GDP does not change much over the industrialization process. And for the economy with $E_{m}=1 / 2$ the leader's level, relative per capita GDP increases. We note that asymptotically the per capita GDP of these three economies relative to the benchmark are 0.016, 6.25 and 25 percent respectively.

Not surprisingly, the rate at which the structural transformation proceeds in each country differs dramatically. Figure 5 shows that differences in non-agricultural efficiency can have large effects on the rate of decline in agriculture's share of employment. For the economy with $E_{m}=1 / 2$ of the leader's level agriculture's share of employment falls to 50 percent in 1989; for the economy with $E_{m}=1 / 4$ of the leader's level agriculture's share of employment falls to 50 percent in 2006; and for the economy with $E_{m}=1 / 8$ of the leader's level, agriculture's share of employment falls to 50 percent in 2014. The date at which agriculture is mechanized in each economy also differs. The first date in which the agricultural technology using capital is operated are 1969, 2006 and 2093 in the three economies. 
Consequently, the model offers a plausible explanation for why a number of countries, particularly those in Latin America, maintained a constant relative income with the leader over the last century; why a number of countries, particularly those in Asia have gained ground relative to the leader over the last fifty years; and why some countries, particularly those in sub-Saharan Africa, continue to lose ground relative to the leader. According to the model, a country that begins the structural transformation in 1950 will lose ground relative to the leader for the next 100 years provided that its nonagricultural efficiency is less than 25 percent that of the leader. Differences of this magnitude in non-agricultural efficiency do not seem implausible, given estimates of TFP for a number of manufacturing and service industries by Bailey (1993), Bailey and Gerbach (1995), and Bailey and Solow (2001) for a set of rich and middle- income countries.

A final point to be taken from this experiment concerns the speed of convergence once industrialization begins. The model predicts that asymptotically a country will converge to a steady-state relative per capita income level associated with the one-sector neoclassical growth model. It is important to emphasize that this convergence is much slower than one would observe in the one-sector neoclassical growth model, if one started out with a small amount of initial capital. The reason is that in our model labor is moved only slowly into the non-agricultural sector, whereas in the standard one-sector neoclassical growth model the entire labor endowment is always in that sector. This matters a lot for the speed of convergence to the steady state.

These findings are not sensitive to the value of the non-agricultural capital share parameter. Changing its value only implies a different relative value of $E_{m}$ above which a 
late starter gains on the earlier starter, and below which the late starter loses ground on the earlier starter. For larger capital share values, this critical value of $E_{m}$ is smaller.

\subsection{Growth Miracles}

The model allows for two interpretations of a growth miracle, by which we mean a doubling of per capita income in a decade or less. One interpretation follows directly from the numerical experiment of the last subsection. In particular, the previous experiment implies that a country that has only recently begun its structural transformation can experience a growth miracle if the efficiency with which it uses resources in the non-agriculture sector is sufficiently high. The second interpretation is not implied by the previous experiments. The second interpretation is that a growth miracle is the result of a large increase in the efficiency with which a relatively unindustrialized economy uses resources in agriculture. We emphasize that there is a real-world basis for this type of change. A substantial literature describes the Green Revolution of the period 1960-2000 in developing countries. (See, for example, Evenson and Gollin 2002.) Crop-level estimates of yield gain from the Green Revolution range from 20 percent to 100 percent. $^{19}$

We proceed to compare the growth miracles associated with each of these sources. We then follow this with a discussion of why the model predicts that growth miracles are a recent phenomenon and limited to poor countries at the date the miracle began.

\footnotetext{
19 The Green Revolution is the term used to describe the application of modern (conventional) plant breeding techniques to the problems of developing countries. Although the biggest gains of the Green Revolution occurred in wheat and rice, advances have Since 1960, more than 8,000 modern crop varieties have been released by breeding programs in the developing world. Rapid TFP increases have been associated with the adoption of new varieties, although measurement problems are predictably acute.
} 
For the growth miracle associated with high efficiency in non-agriculture, we compute the equilibrium path of a country that starts its structural transformation in 1950 and has a level of non-agricultural efficiency equal to the leader. For the growth miracle associated with an increase in agricultural efficiency, we compute the equilibrium path of a country that starts its structural transformation at 1950 and then realizes a one time unexpected increase in the level of its agricultural efficiency equal to the leader's level in 1951. Obviously, how fast this economy grows once it begins its structural transformation depends on the value of its non-agricultural efficiency. For the agricultural miracle economy, we set the value of $E_{m}$ so that it achieves the same increase in its per capita income between 1950 and 1962 as the economy that undergoes a growth miracle associated with a high level of non-agricultural efficiency. The value of $E_{m}$ that satisfies this condition is roughly $1 / 3$ of the leader's level..

Figure 6 shows the path of per capita output of the leader, the non-agriculture miracle economy, and the agriculture miracle economy from 1950 to 2050. We use the label "Non-Ag. Miracle" in the figure to indicate the plot of per capita output for the nonagriculture miracle economy and the label "Ag. Miracle” to indicate the plot of per capita output for the agricultural miracle economy. For comparison purposes we also include the path of per capita GDP for a 1950 late starter that does not undergo an agricultural revolution, and has the same value of $E_{m}$ as the agriculture miracle country, namely $E_{m}$ is roughly $1 / 3$ of the leader's efficiency. For lack of better term, we use the label, "neither" to refer to this economy's plot in Figure 6. Output comparisons are made using the date 2000 prices of the leader. 
By construction, per capita output in the two miracle economies is the same in 1962, which is roughly two times the 1950 level. The paths are extremely different both before and after this date. Before 1962, the economy that undergoes the increase in agricultural efficiency is richer at first, but after 1962 is forever poorer. This is not surprising in light of the properties of the model: agricultural efficiency does not affect a country's asymptotic level of relative per capita income whereas non-agricultural efficiency does.

The miracle generated by an increase in agricultural efficiency is thus short-lived compared to the miracle generated by a high level of non-agricultural efficiency. The effects of the green revolution are not short-lived, however. This is seen by comparing the plots of the country that undergoes a green revolution and the one that does not. One hundred years later, the economy that undergoes a green revolution in 1951 is still richer than the economy that does not but has the same non-agricultural efficiency.

The late starter with the non-agricultural efficiency of the leader grows rapidly over the 1950 to 1985 period. Per capita GDP increases by a factor 13 over this period. The annual growth rate for the economy is not monotonic. Indeed, it is hump-shaped, a pattern that has been documented for the growth miracle experiences of some countries, such as Japan. The annual growth rate increases over the 1950-1960 period, and thereafter decreases until it converges to the steady state growth rate of the leader.

A factor increase of 13 in a 35-year period may seem too large relative to the actual growth miracle experiences of Japan and South Korea. However, neither country was as poor relative to the United Kingdom in 1950 as the model economies in these experiments are. Japan's per capita GDP in 1950 was about 30 percent of the UK level. In the next 35 years, Japan's per capita GDP increased by factor 8 . This is roughly the 
predicted increase for the non-agricultural miracle economy for the 35-year period that follows the date it attains a relative income equal to 30 percent the leader.

The model predicts a slower speed of convergence with a higher value for the capital share parameter in non-agriculture. For example when $\theta=.60$, per capita GDP in the non-agricultural economy increases by a factor 7 in the first 35 years of its transformation. The implied asymptotic ratio of investment in intangible capital to GDP is 36 percent when the capital share is 60 percent, which is well within the range of ratios estimated by Parente and Prescott (2000) using micro data. ${ }^{20}$

Additionally, this experiment effectively assumed that the 1950 starter always had good policy related to its non-agriculture sector in place, even before it began its structural transformation, but this need not be the case. A late starter will undergo a growth miracle following policy reforms that result in a large increase in relative efficiency in non-agriculture. Policy reforms may be gradual, so that increases in relative non-agricultural efficiency may be spread out. This would obviously reduce the speed of convergence.

We conclude this section with the explanation afforded by the model for why growth miracles are a recent phenomenon and why they are limited to poor countries at the time the miracle begins. Growth miracles are a recent phenomenon because the stock of both agricultural and non-agricultural knowledge has increased over time. Thus, a late starter will use less of the available stock of knowledge and be further behind the income of the leader compared to an earlier starter. Should a late starter have a high non-agricultural efficiency once it starts the structural transformation possibly on account of policy

\footnotetext{
${ }^{20}$ This comparison maintains the same per capita GDP level in the late starter relative to the leader at the start of the miracle.
} 
reform, or should it increase its agricultural efficiency, it will realize large increases in per capita output in a precisely because it is so much further behind. Growth miracles are limited to poor countries because rich countries by definition have a high relative efficiency and so use almost all of the stock of available knowledge.

\section{Conclusion}

We have shown in a rather simple model that low agricultural productivity can delay industrialization process for a long period of time. By delaying the industrialization process, such policies result in a country's per capita income falling far behind the leader. Improvements in agricultural productivity can hasten the start of industrialization, and by doing so can have large effects on a country's relative income. Such changes will, in the short-run have a larger impact than a comparable change in non-agriculture. Ultimately, however, the nature of non-agricultural policy determines a country's position to the leader. While we have painted a picture of development that uses fairly broad brush strokes, we believe the important message that emerges is that greater attention to the determinants of productivity in agriculture will greatly enhance our understanding of cross- country differences in income. 


\section{References}

Bailey, Martin. 1993. Competition, Regulation, and Efficiency in Service Industries, Brookings Papers on Economic Activity, Microeconomics 2, 71-130.

Bailey, Martin and H. Gerbach. 1995. Efficiency in Manufacturing and the Need for Global Competition. Brookings Papers on Economic Acrivity, Microeconomics, 307-47.

Bailey, Martin and Robert M. Solow. 2001. International Productivity Comparisons Built from the Firm Level. Journal of Economic Perspectives 15 (Summer), 150-172.

Bernard, Andrew B. and Charles I. Jones. 1996. Comparing Apples to Oranges: Productivity Convergence and Measurement across Industries and Countries. American Economic Review 86(5) 1216-52.

Boserup, Ester. 1965. The Conditions of Agricultural Growth: The Economics of Agrarian Change under Population Pressure. Chicago: Aldine.

Caselli, Francesco and Wilbur John Coleman II. 2001. The U.S. Structural Transformation and Regional Convergence: A Reinterpretation. Journal of Political Economy 109(3) 584-616.

Chari, V.V., Patrick Kehoe, and Ellen McGrattan. 1996. The poverty of nations: A quantitative exploration.” NBER Working Paper 5414.

Chenery, H.B. and M. Syrquin. 1975. Patterns of Development, 1950-1970. London: Oxford University Press.

Clark, Gregory. "Nominal and Real Male Agricultural Wages in England, 1250-1850." Unpublished Manuscript, University of California, Davis, 1998.

Diamond, Jared. 1997. Guns, Germs, and Steel: The Fates of Human Societies. New York: W.W. Norton.

Echevvaria, Cristina. 1995. Agricultural development vs. industrialization: Effects of trade. Canadian Journal of Economics 28 (3): 631-47.

Echevarria, Cristina. 1997. Changes in sectoral composition associated with economic growth. International Economic Review 38 (2): 431-52.

Fei, John C. H. and Gustav Ranis. 1964. Development of the Labor Surplus Economy: Theory and Policy. A Publication of the Economic Growth Center, Yale University. Homewood, Illinois: Richard D. Irwin, Inc.

Geertz, Clifford. 1966. Agricultural Involution: The Process of Ecological Change in Indonesia. Berkeley: University of California Press.

Glomm, Gerhard. 1992. “A Model of Growth and Migration.” Canadian Journal of Economics. 42 (4): 901-22. 
Gollin, Douglas, Stephen L. Parente, and Richard Rogerson. 2000. Farmwork, Homework and International Income Differences. Unpublished Manuscript.

Gollin, Douglas, Stephen L. Parente and Richard Rogerson. 2002. The Role of Agriculture in Development. American Economic Review: Papers and Proceedings. 92(2) 160-64.

Goodfriend, Marvin and John McDermott. 1995. Early Development. American Economic Review 85(1) 116-33.

Hansen, Gary and Edward C. Prescott. 2002. Malthus to Solow. American Economic Review 92(4): 1205-17.

Hayami, Yujiro and Vernon W. Ruttan. 1985. Agricultural Development: An International Perspective. Baltimore: Johns Hopkins University Press.

Irz, Xavier and Terry Roe. 2001. Agricultural productivity and economy-wide growth: investigation in a Ramsey framework. Manuscript: University of Reading, Department of Agricultural and Food Economics.

Johnston, Bruce F. and John W. Mellor. 1961. The role of agriculture in economic development. American Economic Review 51(4): 566-93.

Johnston, Bruce F. and Peter Kilby. 1975. Agriculture and Structural Transformation: Economic Strategies in Late-Developing Countries. New York: Oxford University Press.

Kuznets, Simon. 1966. Modern Economic Growth. New Haven: Yale University Press.

Kongsamut, Piyabha, Sergio Rebelo, and Danyang Xie. 2001. Beyond Balanced Growth. Review of Economic Studies 68(4) 869-882.

Laitner, John. 2000. Structural Change and Economic Growth. Review of Economic Studies 67 (July): 545-561.

Lucas, Robert E. 2001. Some Macroeconomics for the $21^{\text {st }}$ Century. Journal of Economic Perspectives 14: 159-68.

Maddison, Angus. 1995. Monitoring the World Economy: 1820-1992. Paris: Development Centre of the OECD.

Mankiw, N. Gregory, David Romer, and David N. Weil. 1992. A contribution to the empirics of economic growth. Quarterly Journal of Economics 107 (2): 407-37.

Martin, Will and Devashish Mitra. 2001. Productivity Growth and Convergence in Agriculture versus Manufacturing. Economic Development and Cultural Change 49(2) 403-22.

Matsuyama, Kiminori. 1992 Agricultural productivity, comparative advantage, and economic growth. Journal of Economic Theory 58 (2): 317-34.

Mellor, John W. 1986. Agriculture on the road to industrialization. In Development Studies Reconsidered, ed. John P. Lewis and Valeriana Kallab. Washington DC: Overseas Development Council. 
Ngai, Rachel. 1999. Barriers and the Transition to Modern Growth. Unpublished Manuscript, University of Pennsylvania.

Parente, Stephen L. and Edward C. Prescott. 1994. Barriers to technology adoption and development. Journal of Political Economy 102 (2): 298-321.

Parente, Stephen L. and Edward C. Prescott. 2000. Barriers to Riches. Cambridge: MIT Press.

Parente, Stephen L., Richard Rogerson, and Randall Wright. 2000. Home work in development economics: home production and the wealth of nations. Journal of Political Economy.

Schultz, T. W. 1953. The Economic Organization of Agriculture. New York: McGraw-Hill.

Schultz, T. W. 1964. Transforming Traditional Agriculture. New Haven: Yale University Press.

Schultz, T. W. 1968. Economic Growth and Agriculture. New York: McGraw-Hill.

Syrquin, Moshe. 1988. Patterns of structural change. Chapter 7 in Handbook of Development Economics, Vol. I, ed. H. Chenery and T.N. Srinivasan. Amsterdam: Elsevier Science Publishers.

Timmer, C. Peter. 1988. The agricultural transformation. Chapter 8 in Handbook of Development Economics, Vol. I, ed. H. Chenery and T.N. Srinivasan. Amsterdam: Elsevier Science Publishers. 
Table 1: Regression results: Changes in agricultural productivity and their relationship to changes in agriculture's share of employment, 19601990, for 62 developing countries.

Dependent Variable: Change in Log of Agriculture's Share of Employment

Regression Statistics

Multiple R

0.423

R Square

0.179

Adjusted R Square

0.137

Standard Error

0.093

Observations

62

Significance - F

0.009

ANOVA

\begin{tabular}{lllll}
\hline & $D f$ & $S S$ & $M S$ & $F$ \\
\hline Regression & 3 & 0.109 & 0.036 & 4.218 \\
Residual & 58 & 0.501 & 0.009 & \\
Total & 61 & 0.610 & & \\
\hline \multicolumn{5}{l}{ Standard } \\
& Coefficients & Error & t Stat & P-value \\
\hline Intercept & -0.052 & 0.035 & -1.479 & 0.145 \\
Change in log ag output per person & -0.150 & 0.072 & -2.076 & 0.042 \\
Ag Output per Person 1970 & $-1.6 \mathrm{E}-4$ & $8 \mathrm{E}-05$ & -1.984 & 0.052 \\
Dummy: 1960 data & -0.075 & 0.024 & -3.018 & 0.004 \\
\hline
\end{tabular}


Table 2: Calibration Parameters

\begin{tabular}{|c|c|}
\hline Parameter & Value \\
\hline $\begin{array}{c}\text { Preference } \\
\text { Parameters }\end{array}$ & \\
\hline $\bar{a}$ & 1.0 \\
\hline$\beta$ & .96 \\
\hline $\begin{array}{c}\text { Non-Agriculture } \\
\text { Sector Parameters }\end{array}$ & \\
\hline$\varepsilon$ & .0001 \\
\hline$\theta$ & .50 \\
\hline$E_{m}$ & 0.55 \\
\hline$\delta$ & .065 \\
\hline$\gamma_{m}$ & .007 \\
\hline $\begin{array}{c}\text { Agriculture Sector } \\
\text { Parameters }\end{array}$ \\
\hline$\alpha$ & .7 \\
\hline$\phi$ & .1 \\
\hline$\mu$ & .6 \\
\hline$\gamma_{a}$ & .0074 \\
\hline$E_{a}$ & .993 \\
\hline
\end{tabular}

Table 3: Agricultural TFP and Industrialization

\begin{tabular}{|l|l|l|}
\hline Date & $E_{a}$ & Relative Income \\
\hline 1800 & .51 & $42.0 \%$ \\
\hline 1850 & .35 & $21.0 \%$ \\
\hline 1900 & .24 & $11.0 \%$ \\
\hline 1950 & .17 & $5.5 \%$ \\
\hline 2000 & .12 & $2.7 \%$ \\
\hline
\end{tabular}


Figures

Figure 1

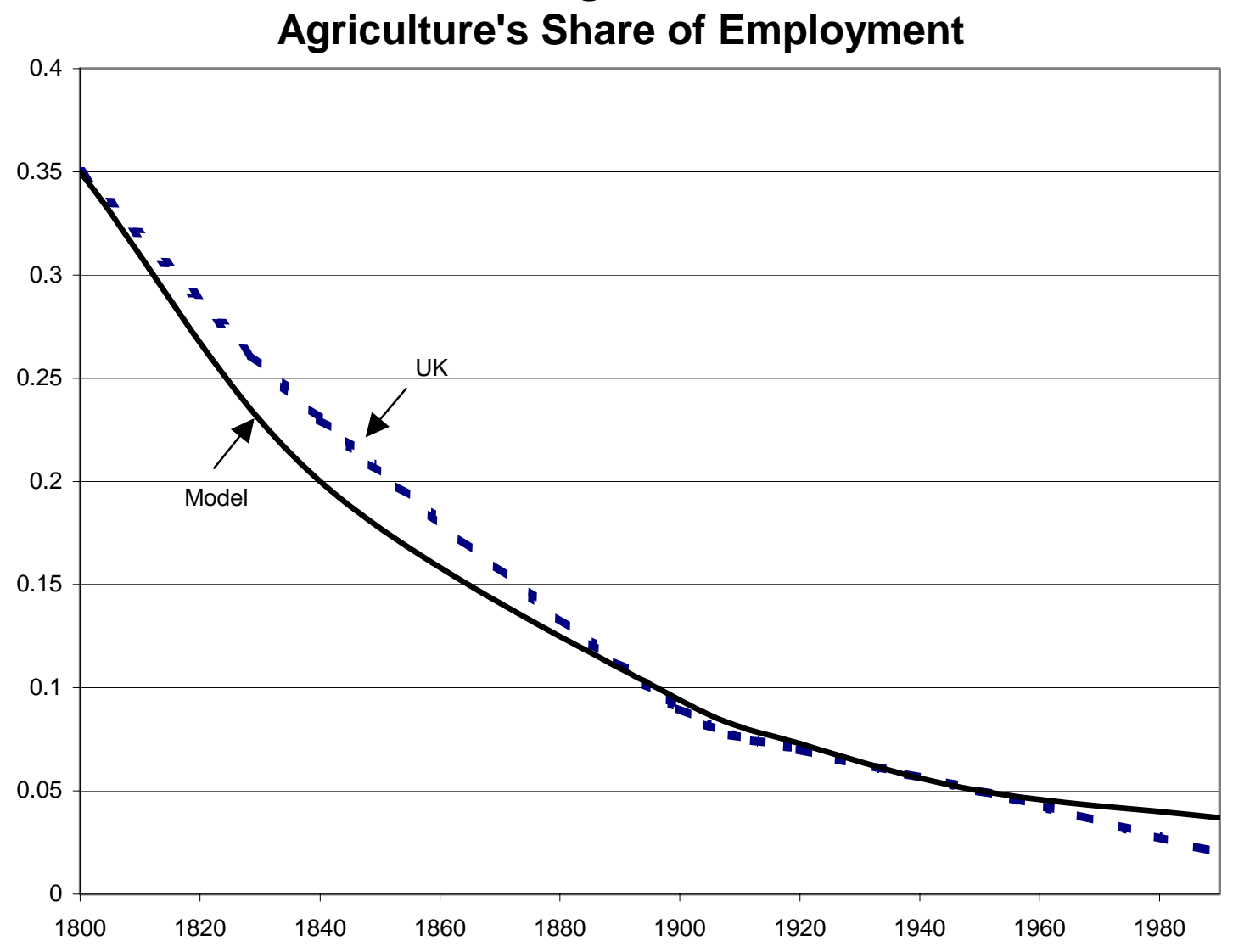


Figure 2

Per Capita GDP Relative to $\mathbf{1 8 2 0}$

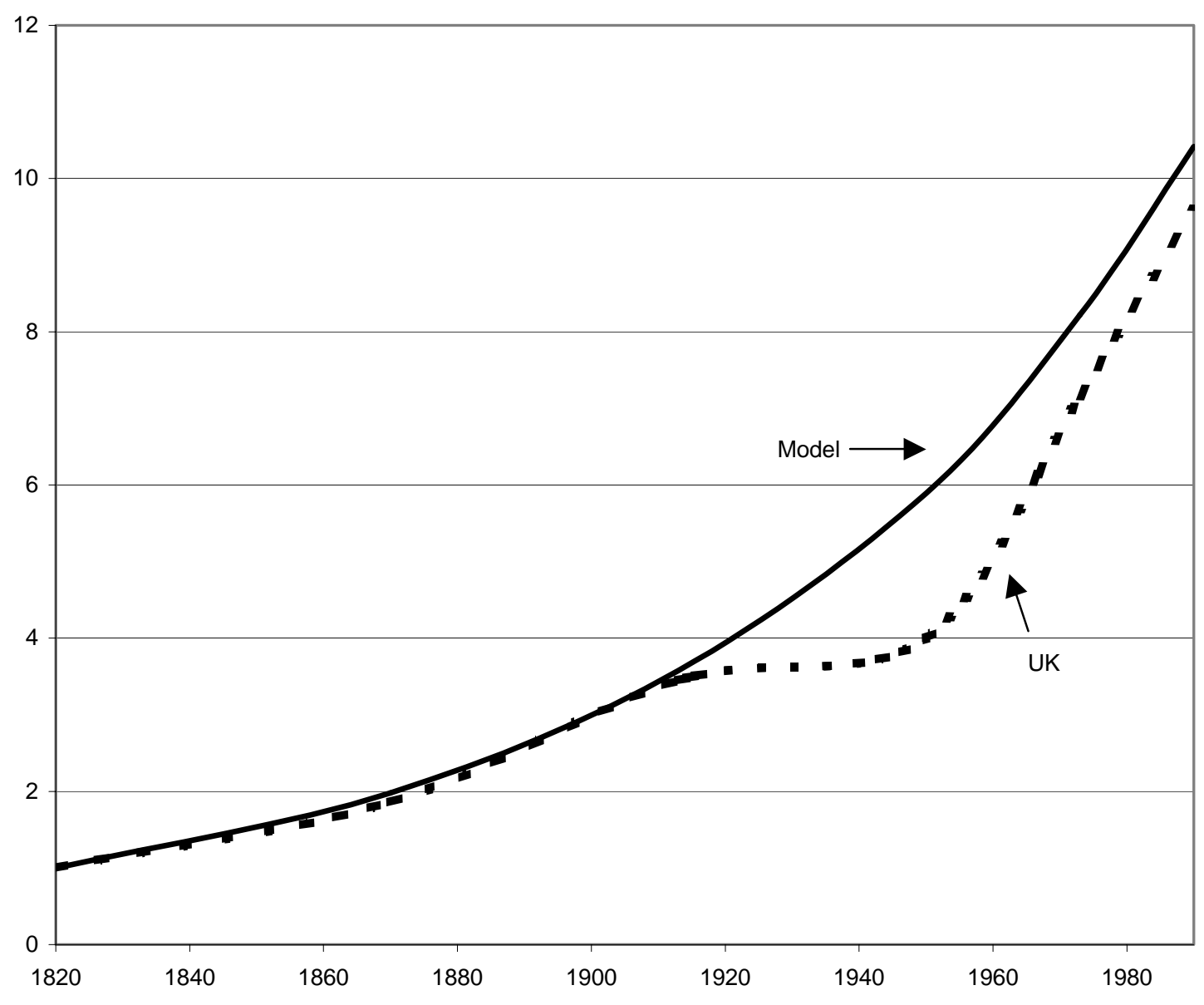


Figure 3

Agriculture's Share of GDP

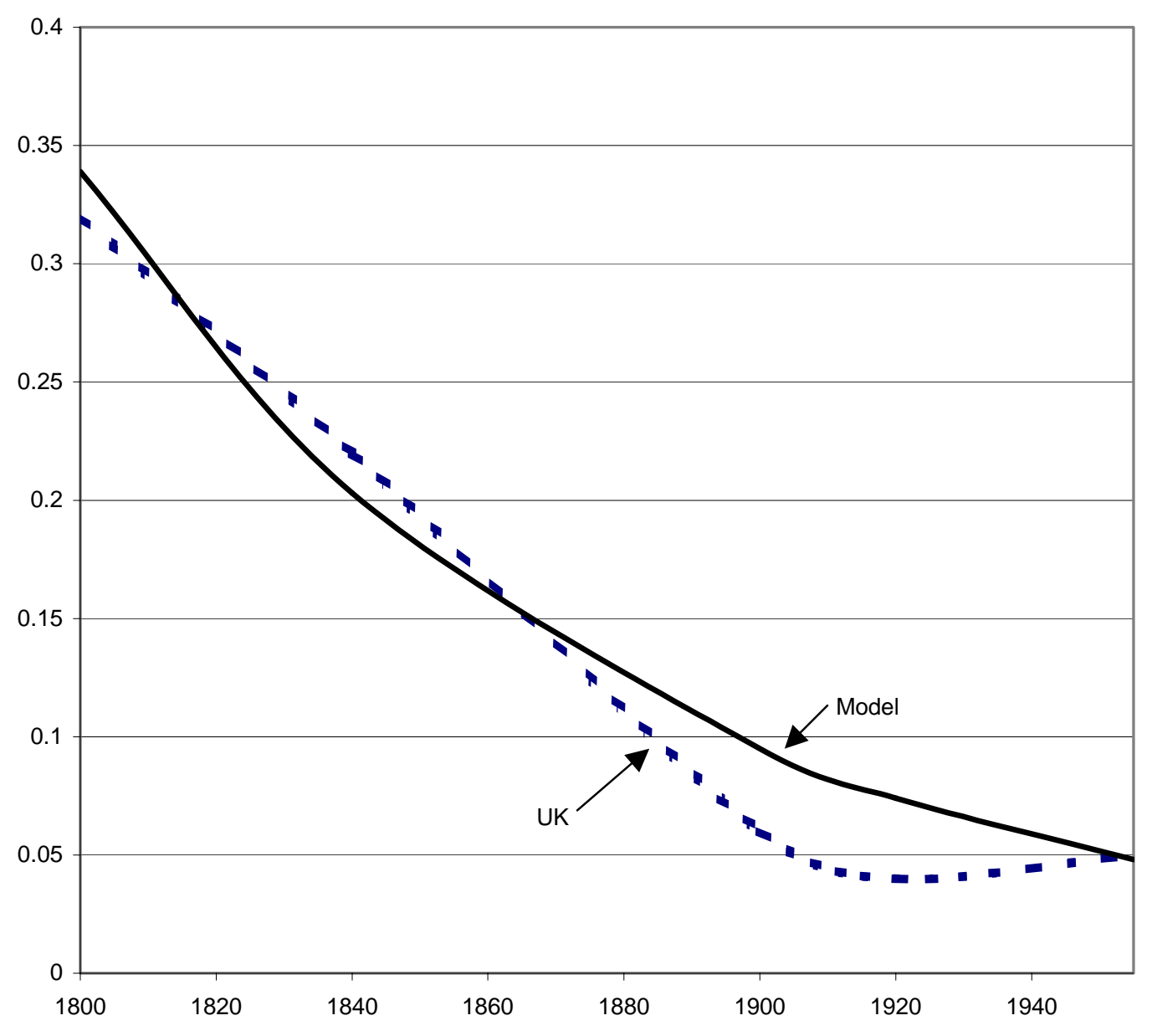


Figure 4

Relative Per Capita GDP For Late Starters

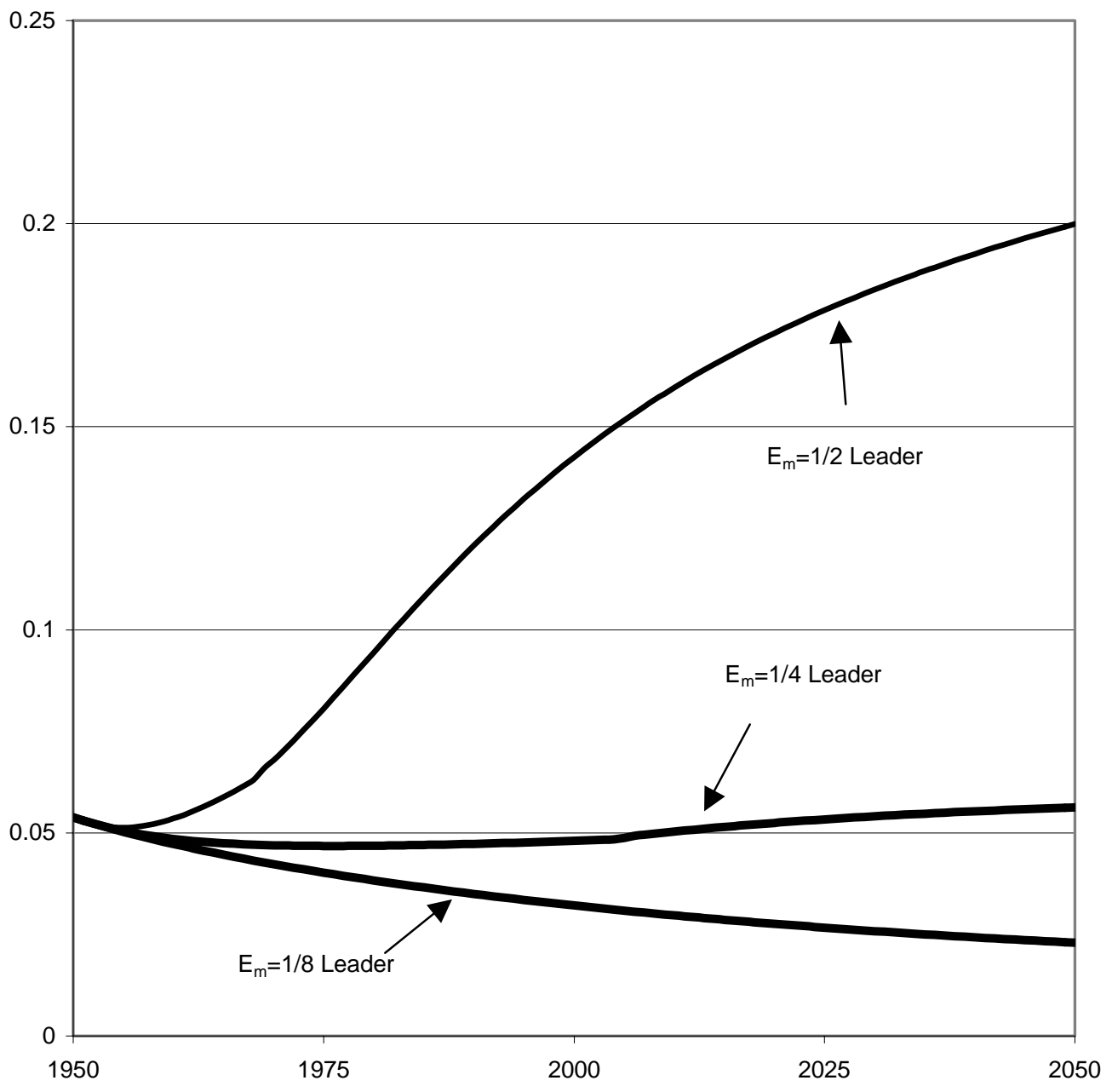


Figure 5

Agriculture Employment Shares for Late Starters

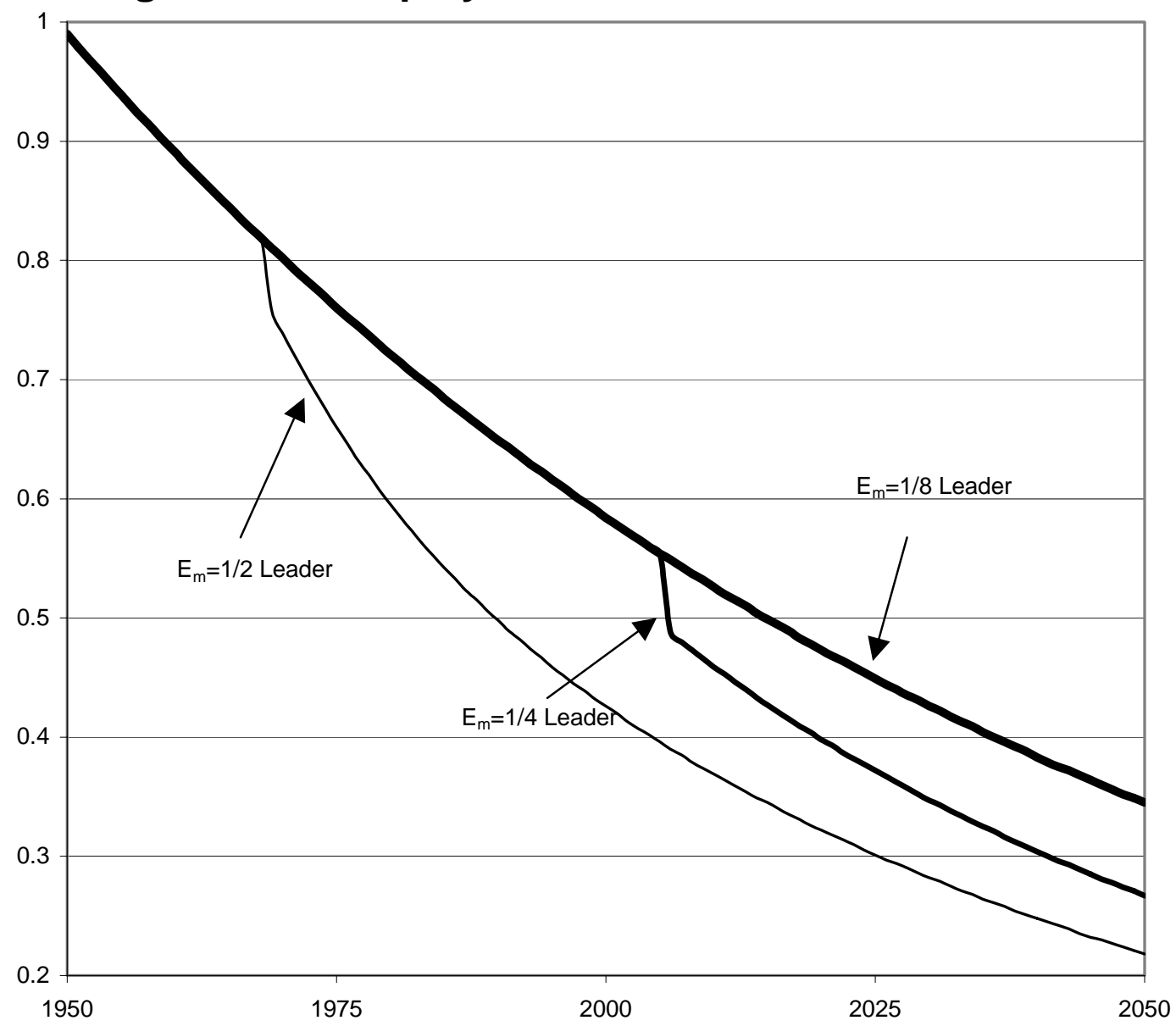


Figure 6

\section{Growth Miracles}

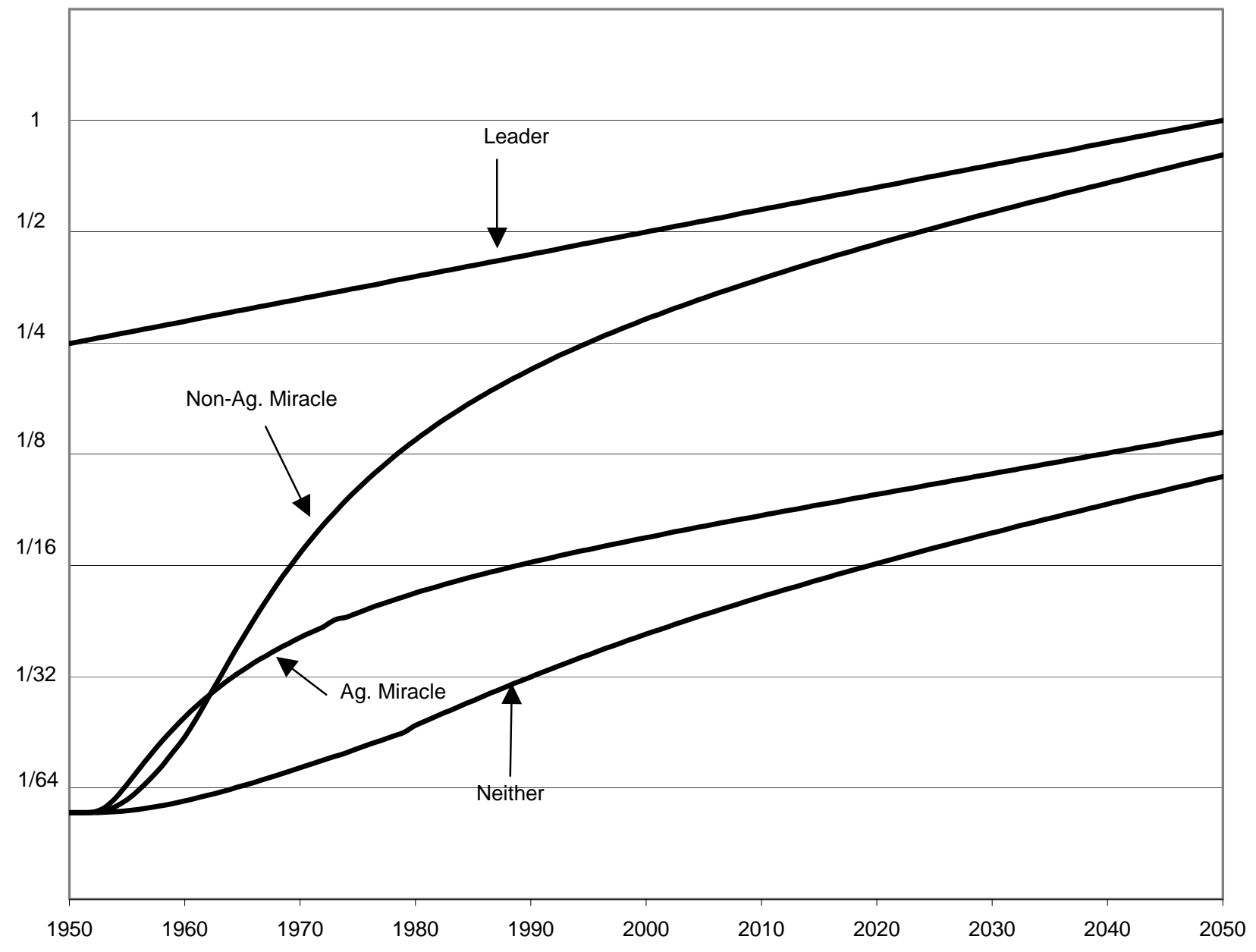

